\title{
Predicting the Enthalpy of Vaporization and Calculating the Entropy of Vaporization of 87 Octane Gasoline Using Vapor Pressure
}

\author{
Shawn M. Abernathy, Kelly R. Brown \\ Department of Chemistry, Howard University, Washington DC, USA \\ Email: SAbernathy@Howard.edu
}

How to cite this paper: Abernathy, S.M. and Brown, K.R. (2016) Predicting the Enthalpy of Vaporization and Calculating the Entropy of Vaporization of 87 Octane Gasoline Using Vapor Pressure. Open Access Library Journal, 3: e2954.

http://dx.doi.org/10.4236/oalib.1102954

Received: August 15, 2016

Accepted: September 10, 2016

Published: September 13, 2016

Copyright $\odot 2016$ by authors and Open Access Library Inc.

This work is licensed under the Creative Commons Attribution International

License (CC BY 4.0).

http://creativecommons.org/licenses/by/4.0/

\section{(c) (i) Open Access}

\begin{abstract}
The vapor pressure (VP) of 87 grade gasoline was measured using an enhanced VP acquisition system over a temperature range of approximately $19.0^{\circ} \mathrm{C}(292.2 \mathrm{~K})$ and $69.0^{\circ} \mathrm{C}(342.2 \mathrm{~K})$. The empirical data were used to predict the thermodynamic entities the enthalpy of vaporization $\left(\Delta H_{\text {vap }}\right)$ and the entropy of vaporization $\left(\Delta S_{\text {vap }}\right)$ of gasoline. The results of this investigation yielded a $\Delta H_{\text {vap }}$ value of $35.1 \mathrm{~kJ} / \mathrm{mol}$ and $\Delta S_{\text {vap }}$ of $102.5 \mathrm{~J} / \mathrm{mol} \cdot \mathrm{K}$. The value of $\Delta H_{\text {vap }}$ was in excellent agreement with the findings of a prior study (Balabin et al., 2007), which produced a $\Delta H_{\text {vap }}$ values of 37.3 $\mathrm{kJ} / \mathrm{mol}$ and $35.4 \mathrm{~kJ} / \mathrm{mol}$. The enthalpy and entropy of vaporization of $\mathrm{n}$-heptane $(37.2$ $\mathrm{kJ} / \mathrm{mol}$ and $100.1 \mathrm{~J} / \mathrm{mol} \cdot \mathrm{K})$ and $\mathrm{n}$-octane $(39.1 \mathrm{~kJ} / \mathrm{mol}$ and $98.3 \mathrm{~J} / \mathrm{mol} \cdot \mathrm{K})$ were also determined after acquiring VP data for the two VOCs. The empirical results for $\mathrm{n}$-heptane and n-octane were also in excellent agreement with the literature. These favorable comparisons strengthen the capacity of our system for acquiring the VP data for pure and volatile multi-component mixtures.
\end{abstract}

\section{Subject Areas}

Physical Chemistry

\section{Keywords}

Gasoline, Vapor Pressure (VP), Enthalpy of Vaporization, Entropy of Vaporization, Volatile Organic Compounds (VOCs)

\section{Introduction}

Automotive gasoline is a major product manufactured by the petroleum industry. The vapor pressure (VP) is a key physical property of automotive gasoline as well as avia- 
tion fuels. Gasoline is a petroleum fuel that is highly volatile. It is refined product of crude oil consisting of a mixture of hydrocarbons, additives, and blending agents. The VP is critically important for both automotive and aviation gasoline; this is due to these fuels being manufactured as liquids, but consumed in the vapor phase. Thus, high volatility is a prerequisite for a gasoline to ensure sufficient engine start-up, warm-up and acceleration under routine driving and flying conditions [1] [2]. The VP of gasoline is also vital for predicting the concentration of volatile compounds discharged into the atmosphere via the combustion of the fuel.

There are a number of methods for determining the VP and they are somewhat timeconsuming. The Reid vapor pressure (RVP) is typically the measurement of choice for ascertaining the volatility of commercial gasoline in the refinery industry. The protocol and apparatus for acquiring the RVP are well described in ASTM D-323. The RVP is the absolute vapor pressure exerted by a mixture as determined at a temperature of $100^{\circ} \mathrm{F}\left(37.8^{\circ} \mathrm{C} / 311.0 \mathrm{~K}\right)$ and a vapor to liquid ratio of $4: 1$. It differs from the true vapor pressure (TVP) which is described as the pressure exerted by a vapor in equilibrium with its liquid phase at a specific temperature. Measuring the TVP is probably more conducive for determining the concentration of combustion contaminants emitted into the atmosphere since a maximum threshold has been imposed for the VP of gasoline in order to restrict air pollution [1]-[3].

The petroleum industry relies heavily on performing simulations in order to test and optimize processes prior to the manufacturing of gasoline [4]. This is done in order to ensure the gasoline to meet technological specifications and stringent environmental regulations mandated to improve air quality. High quality empirical VP data, as a function of temperature, and thermodynamic information are crucial input parameters for the optimization of these models. The enthalpy of vaporization $\left(\Delta H_{\text {vap }}\right)$ is one of these vital thermodynamic parameters since it is one of several characteristics that describe the volatility of a fuel. Predicting the amount of heat required to evaporate (i.e. vaporizes) a specific quantity of gasoline to produce an ignitable air-fuel-vapor mixture is of the utmost importance for automobile engines; this is particular important to know before formulation of a gasoline blend and it being released to market [4]. Equally important is the use of analytical equations to produce input parameters for models. These equations also serve to compute stand-alone thermodynamic information of gasoline blends. An excellent outline of numerous analytical expression used in this capacity was summarized by Riazi et al. [3].

There is a large database of enthalpy of vaporization $\left(\Delta H_{\text {vap }}\right)$ values for pure volatile organic compounds (VOCs). This information can be readily found in reference books such as the CRC (Chemical Rubber Company) Handbook of Chemistry and Physics and Perry \& Green Chemical Engineers Handbook. However, there is a lack of $\Delta H_{\text {vap }}$ data on complex mixtures such as gasoline and aviation fuel; this may be due to earlier studies not being well developed as suggested by Chapka et al. [5]. Nevertheless, there is a plethora of Reid and true vapor pressure data on numerous blends of gasoline [6]. The Clausius-Clapeyron equation (i.e. plot of $\ln P$ vs. $1 / T(K)$ ) could be readily applied 
to this gasoline VP data in order to create preliminary $\Delta H_{\text {vap }}$ values as well as construct a database. This precursory information would facilitate filling this particular knowledge gap.

The intent of this study was to amass high quality TVP data of 87 grade gasoline over a series of temperatures, i.e. as a function of temperature. The VP is a crucial physical property that is closely associated with volatility. It can be used to approximate a number of thermodynamic entities. Hence, the gasoline VP data acquired in this work were employed to predict the enthalpy of vaporization $\left(\Delta H_{\text {vap }}\right)$ and compute the entropy of vaporization $\left(\Delta S_{\text {vap }}\right)$. Although the Clausius-Clapeyron is a classic method for calculating $\Delta H_{\text {vap }}$ of pure liquids, it is well suited for this investigation. VP data were also acquired for $\mathrm{n}$-heptane and $\mathrm{n}$-octane in order to optimize the performance of this novel VP acquisition system and concomitantly serving as references data. This type of meticulous evaluation is necessary to ensure the reliability of the methodology and empirical results generated from this novel system. The VP data (water, ethanol, and toluene) and the computed thermodynamic data presented in an earlier paper are incorporated in this investigation due to coinciding data collection intervals [7].

\section{Experimental}

\subsection{Materials}

The gasoline sample used in this work was purchased at a local Sunoco gas station, and had an octane rating of 87 . The composition and information on the ingredients of the gasoline are listed on its material safety data sheet. The VOCs n-heptane (99\% HPLC grade), n-octane, anhydrous ethanol (EtOH), toluene were purchased from the Aldrich Chemical Company and Fischer Scientific. These materials, gasoline and chemicals, were used without purification and handled using proper safety measures as specified from their Material Safety Data Sheet.

\subsection{Methodology}

The VP data of gasoline along with n-heptane (99\% HPLC grade), n-octane, distilled water, $\mathrm{EtOH}$, and toluene was measured utilizing an enhanced VP acquisition system, which is an innovative modification of the "Boiling-Point Method" apparatus. In this procedure, liquid vapors are in equilibrium with its boiling liquid at a specific externally applied pressure. The method is well recognized in the literature [8]. A portable Welch GEM direct-drive vacuum pump was used as the external vacuum source to vary the pressure of the acquisition system. A digital vacuum regulator (DVR) manufactured by J-KEM Scientific, connected to the vacuum pump, was utilized to accurately control the pressure $( \pm 0.5$ torr $)$ above the gasoline sample $(100 \mathrm{ml})$ in the liquid reservoir $(250$ $\mathrm{ml}$ round-bottom flask).

The heating of the gasoline sample was carried out using a Büchi model B-490 water bath interfaced with a J-KEM Scientific digital temperature controller (DTC). The liquid reservoir was submerged in the water bath to equilibrate the sample at a predetermined set temperature in which the VP would be measured. The temperature of the 
sample was measured by the thermocouple sensor component $\left( \pm 0.5^{\circ} \mathrm{C}\right)$ of the DTC, which was positioned in the middle of the sample. The DVR and DTC were interfaced to a desktop PC, which logged into an excel spreadsheet the temperature and pressure data in real-time every 20 seconds. The resulting VP data can be readily evaluated in the excel spreadsheet or exported for processing using the KaleidaGraph software package. A minimum of nine VP measurements were acquired at each specified temperature to ensure reproducibility of the data; this would correspond to a total minimum acquisition time of three minutes. There were between nine and 30 VP measurements acquired at each temperature interval throughout this investigation. The standard deviation in pressure (torr) and temperature (C) is shown in Table 1 for water and the each VOC. These units of temperature and pressure were chosen to be consisted with the literature in which they were compared. A detailed illustration of the enhanced VP acquisition system was depicted in a prior publication in this journal [7].

\section{Result and Discussion}

In this investigation, the enhanced VP acquisition system was used to collect empirical VP data of Sunoco 87 grade gasoline, n-heptanes, and n-octane. Calibration of the system using distilled water, EtOH, and toluene have also been reported. The information also served as a reference indicator, and is displayed with all the results of this investigation in Table 1. It can be readily observed that the experimental data is inline with the literature data [9], which are shown in parentheses in Table 1.

Determining the vapor pressure of a pure liquid or mixture is rooted in understanding the existence of a liquid-vapor boundary. A dynamic equilibrium exists between the two phases, i.e. the liquid and vapor phases; this is an interface in which the pressures and temperatures of the two phases can co-exist. The Clapeyron equation is an exact expression for the slope of the liquid-vapor phase boundary. Equation (1) represents the equilibrium that occurs between the liquid-vapor phases, where the slope of the boundary is $\mathrm{d} P / \mathrm{d} T$ :

$$
\frac{\mathrm{d} P}{\mathrm{~d} T}=\frac{\Delta H_{\text {vap }}}{T \Delta V_{\text {vap }}}
$$

In this equation, $\Delta H_{\text {vap }}$ is the change in the enthalpy of vaporization and $T$ is the absolute the temperature in Kelvin. The variable $\Delta V_{\text {vap }}$ correspond to the change in molar volume of vaporization, where we assume the gas phase behaves as an ideal gas. If we infer that $\Delta V_{\text {vap }} \approx V_{\text {vap }}$ and use the ideal equation of state, we can derive Equation (2):

$$
\frac{\mathrm{d} P}{\mathrm{~d} T}=\frac{\Delta H_{\mathrm{vap}} P}{R T^{2}}
$$

The variable $P$ in Equation (2) is the vapor pressure and $R$ is the gas constant (8.314 $\mathrm{J} / \mathrm{mol} \cdot \mathrm{K})$. By separating the variables $P$ and $T$, integration of Equation (2) yields the Clausius-Clapeyron equation; this well known phase equilibrium expression is represented by Equation (3)

$$
\ln P=-\frac{\Delta H_{\text {vap }}}{R T}+C
$$


Table 1. Summary of predicted $\Delta H_{\text {Vap }}$ and computed $\Delta S_{\text {Vap }}$ results from VP data amassed from the Enhanced VP Acquisition System.

\begin{tabular}{|c|c|c|c|}
\hline Compound & Temperature ${ }^{\circ} \mathrm{C}$ (Lit. value) & Pressure Torr. (Lit. value) & $\Delta \mathrm{H}_{\mathrm{V}_{\text {ap }}}$ and $\Delta \mathrm{S}_{\mathrm{Vap}}$ \\
\hline \multirow{11}{*}{ Water } & $15.2 \pm 0.1$ & $12.5 \pm 0.1(12.95)$ & $43.3 \mathrm{~kJ} / \mathrm{mol}$ \\
\hline & $21.0 \pm 0.1$ & $18.8 \pm 0.2(18.65)$ & $116.0 \mathrm{~J} / \mathrm{mol} \cdot \mathrm{K}$ \\
\hline & $29.6 \pm 0.1$ & $31.6 \pm 0.2(34.86)$ & Slope $=-5215.1$ \\
\hline & $39.8 \pm 0.3$ & $55.0 \pm 0.3(54.16)$ & $\mathrm{R}=0.99989$ \\
\hline & $49.7 \pm 0.1$ & $91.5 \pm 0.6(91.14)$ & \\
\hline & $59.5 \pm 0.2$ & $148.1 \pm 0.8(146.0)$ & \\
\hline & $69.3 \pm 0.1$ & $230.9 \pm 0.1(226.7)$ & \\
\hline & $79.3 \pm 0.1$ & $351.6 \pm 2.3(345.4)$ & \\
\hline & $88.9 \pm 0.3$ & $520.1 \pm 3.6(504.2)$ & \\
\hline & $94.7 \pm 0.1$ & $636.8 \pm 1.9(627.0)$ & \\
\hline & $99.4 \pm 0.1$ & $766.1 \pm 0.2(743.85)$ & \\
\hline \multirow{4}{*}{$\mathrm{EtOH}$} & $18.0 \pm 0.1(19.0)$ & $39.2 \pm 0.5(40)$ & $42.0 \mathrm{~kJ} / \mathrm{mol}$ \\
\hline & $33.9 \pm 0.1(34.9)$ & $96.2 \pm 0.7(100)$ & $119.5 \mathrm{~J} / \mathrm{mol} \cdot \mathrm{K}$ \\
\hline & $62.0 \pm 0.1(63.5)$ & $387 \pm 0.5(400)$ & Slope $=-5056.6$ \\
\hline & $78.1 \pm 0.1(88.4)$ & $761.6 \pm 5.0(760)$ & $\mathrm{R}=0.99998$ \\
\hline \multirow{4}{*}{ Heptane } & $21.9 \pm 0.2(22.3)$ & $39.8 \pm 0.2(40)$ & $37.2 \mathrm{~kJ} / \mathrm{mol}$ \\
\hline & $41.2 \pm 0.2(41.8)$ & $98.7 \pm 0.7(100)$ & $100.1 \mathrm{~J} / \mathrm{mol} \cdot \mathrm{K}$ \\
\hline & $76.6 \pm 0.2(78.0)$ & $395.9 \pm 2.6(400)$ & Slope $=-4476.6$ \\
\hline & $91.5 \pm 0.2(98.4)$ & $754.8 \pm 0.4(760)$ & $\mathrm{R}=0.9994$ \\
\hline \multirow{5}{*}{ Octane } & $19.0 \pm 0.1(19.2)$ & $10.5 \pm 0.1(10)$ & $39.1 \mathrm{~kJ} / \mathrm{mol}$ \\
\hline & $44.9 \pm 0.03(45.1)$ & $43.4 \pm 0.9(40)$ & $98.3 \mathrm{~J} / \mathrm{mol} \cdot \mathrm{K}$ \\
\hline & $65.2 \pm 0.3(65.7)$ & $107.6 \pm 1.3(100)$ & Slope $=-4698.5$ \\
\hline & $103.3 \pm 0.4(104.0)$ & $402.2 \pm 2.1(400)$ & $\mathrm{R}=0.99935$ \\
\hline & $124.5 \pm 0.01(125.0)$ & $758.0 \pm 2.3(760)$ & \\
\hline \multirow{4}{*}{ Toluene } & $30.4 \pm 0.3(31.8)$ & $39.8 \pm 0.3(40)$ & $35.3 \mathrm{~kJ} / \mathrm{mol}$ \\
\hline & $49.9 \pm 1.8(51.9)$ & $123.5 \pm 1.5(100)$ & $92.0 \mathrm{~J} / \mathrm{mol} \cdot \mathrm{K}$ \\
\hline & $89.9 \pm 0.5(89.5)$ & $418.2 \pm 4.5(400)$ & Slope $=-4247.5$ \\
\hline & $107.9 \pm 1.5(110.6)$ & $759.7 \pm 0.1(760)$ & $\mathrm{R}=0.99548$ \\
\hline \multirow{6}{*}{ Gasoline } & $18.9 \pm 0.2$ & $99.7 \pm 0.5$ & $35.1 \mathrm{~kJ} / \mathrm{mol}$ \\
\hline & $30.5 \pm 1.5$ & $127.4 \pm 2.2$ & $102.5 \mathrm{~J} / \mathrm{mol} \cdot \mathrm{K}$ \\
\hline & $39.7 \pm 0.6$ & $247.2 \pm 1.7$ & Slope $=-4223.2$ \\
\hline & $51.9 \pm 0.5$ & $389.0 \pm 2.9$ & $\mathrm{R}=0.99136$ \\
\hline & $60.8 \pm 0.6$ & $560.6 \pm 7.6$ & \\
\hline & $69.1 \pm 0.4$ & $758.4 \pm 0.2$ & \\
\hline
\end{tabular}


The enthalpy of vaporization can be predicted from Equation (3) from a plot of the natural logarithm of pressure $(\ln P)$ versus the reciprocal absolute temperature $(1 / \mathrm{K})$. A straight line is generated with a slope equal to $-\Delta H_{\text {vap }} / R$ and an intercept denoted by the constant $C$ [8]. This is the methodology employed in this study to predict $\Delta H_{\text {vap }}$ Equally, the value of $\Delta S_{\text {vap }}$ for each liquid was computed using Trouton's Law and is expressed by Equation (4):

$$
\Delta S_{\text {vap }}=\Delta H_{\text {vap }} / T_{b, \text { Kelvin }}
$$

Figure 1 illustrate plots of the empirical VP data of the calibration and reference liquids water, $\mathrm{EtOH}$, and toluene as the $\ln P$ vs. $1 / T(K)$. A linear least square regression fit was applied to each set of VP data and is depicted in Figure 1. Using the water VP data as an example, a linear least square regression fit of the data results in an equation for the line of best fit equal to $y=20.657-5215.1 x$. This can be translated to the form of Equation (5) as:

$$
\ln P=\frac{-5215.1}{T}+C
$$

The enthalpy of vaporization $\left(\Delta H_{\text {vap }}\right)$ and entropy of vaporization $\left(\Delta S_{\text {vap }}\right)$ of the reference liquids were determined prior to that of the 87 grade gasoline. This was completed in order to acquire the optimal VP data as well as ensure maximum performance of the VP acquisition system. Using the slope of the linear square regression fit of the water VP data, a value of $43.4 \mathrm{~kJ} \cdot \mathrm{mol}^{-1}$ was evaluated as the enthalpy of vaporization ( $\Delta H_{\text {vap }}$ ) of water; this deviated by approximately $1.0 \%$ from the literature value [9]. The entropy of vaporization was determined using Equation (4) (Trouton's Law) by dividing $\Delta H_{\text {vap }}$ of water by its normal boiling point temperature in Kelvin $\left(100.0^{\circ} \mathrm{C}, 373.2 \mathrm{~K}\right)$; this resulted in a $\Delta S_{\text {vap }}$ of $116.3 \mathrm{~J} / \mathrm{mol} \cdot \mathrm{K}$ for water. The predicted values of $\Delta H_{\text {vap }}$ for EtOH and toluene were $42.0 \mathrm{~kJ} / \mathrm{mol}$ and $35.3 \mathrm{~kJ} / \mathrm{mol}$ respectively using the line of best fit through the empirical VP data. The $\Delta H_{\text {vap }}$ of EtOH and toluene deviated by 1.0 and 5.4\% respectively, and were in excellent agreement with the literature [9]. The computed values for $\Delta S_{\text {vap }}$ of EtOH and toluene were $119.5 \mathrm{~J} / \mathrm{mol} \cdot \mathrm{K}$ and $35.3 \mathrm{~J} / \mathrm{mol} \cdot \mathrm{K}$ respectively. Although this data is from a previously published study by the authors, the inclusion of it in this paper strengthens and validates the performance as well as the use of the enhanced VP acquisition system.

The VP measurements were obtained for Sunoco 87 grade gasoline. The data was subsequently used to predict the $\Delta H_{\text {vap }}$ and $\Delta S_{\text {vap }}$ of the fuel. These thermodynamic entities were predicted in the same manner as the water and VOCs references. A linear least square fit of the gasoline VP data resulted in a slope of -4223.3 as shown in Figure 2; this produced a $\Delta H_{\text {vap }}$ of $35.1 \mathrm{~kJ} / \mathrm{mol}$ and $\Delta S_{\text {vap }}$ of $102.5 \mathrm{~J} / \mathrm{mol} \cdot \mathrm{K}$. The normal boiling point of the gasoline was determined to be approximately $69.1^{\circ} \mathrm{C}(342.3 \mathrm{~K})$. This is the temperature in which the gasoline boiled at approximately 760 torr, i.e. the normal boiling point. The values of $\Delta H_{\text {vap }}$ for the two gasoline samples used in the study performed by Balabin et al. were $37.3 \mathrm{~kJ} / \mathrm{mol}$ and $35.4 \mathrm{~kJ} / \mathrm{mol}$ [10]. These values compare favorable to the result of $35.1 \mathrm{~kJ} / \mathrm{mol}$ predicted in this investigation. This clearly indicates the viability and efficiency of the enhanced VP acquisition system for 
Plots of the InP vs. $1 / T(K)$ for Water, Ethanol (EtOH), and Toluene vapor pressure data
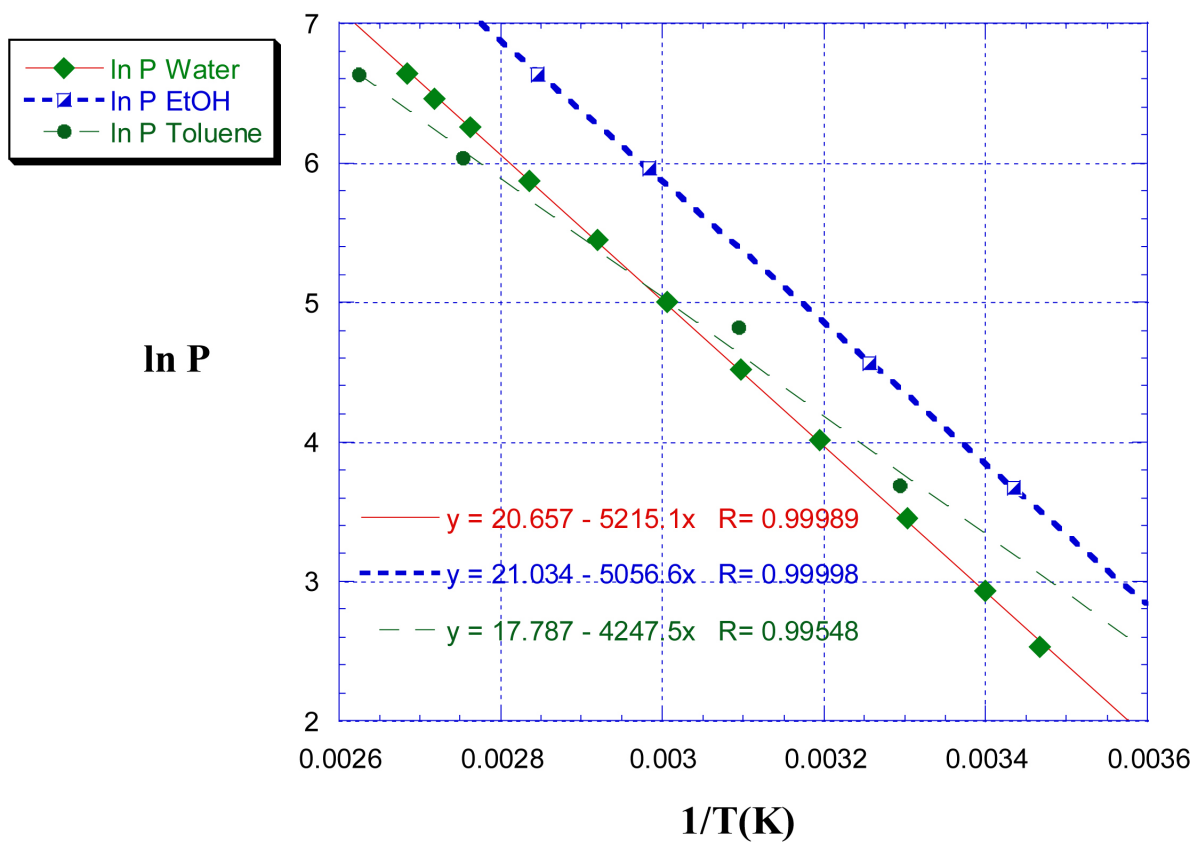

Figure 1. Plots of the $\ln P$ vs. $1 / T(K)$ of Water, Ethanol, and Toluene and their linear least squares regression fit of the empirical VP data. Water, EtOH, and Toluene data are represented by green diamonds, half-filled (white/blue) squares, and green circles respectively.

Plot of the In P vs. 1/T(K)

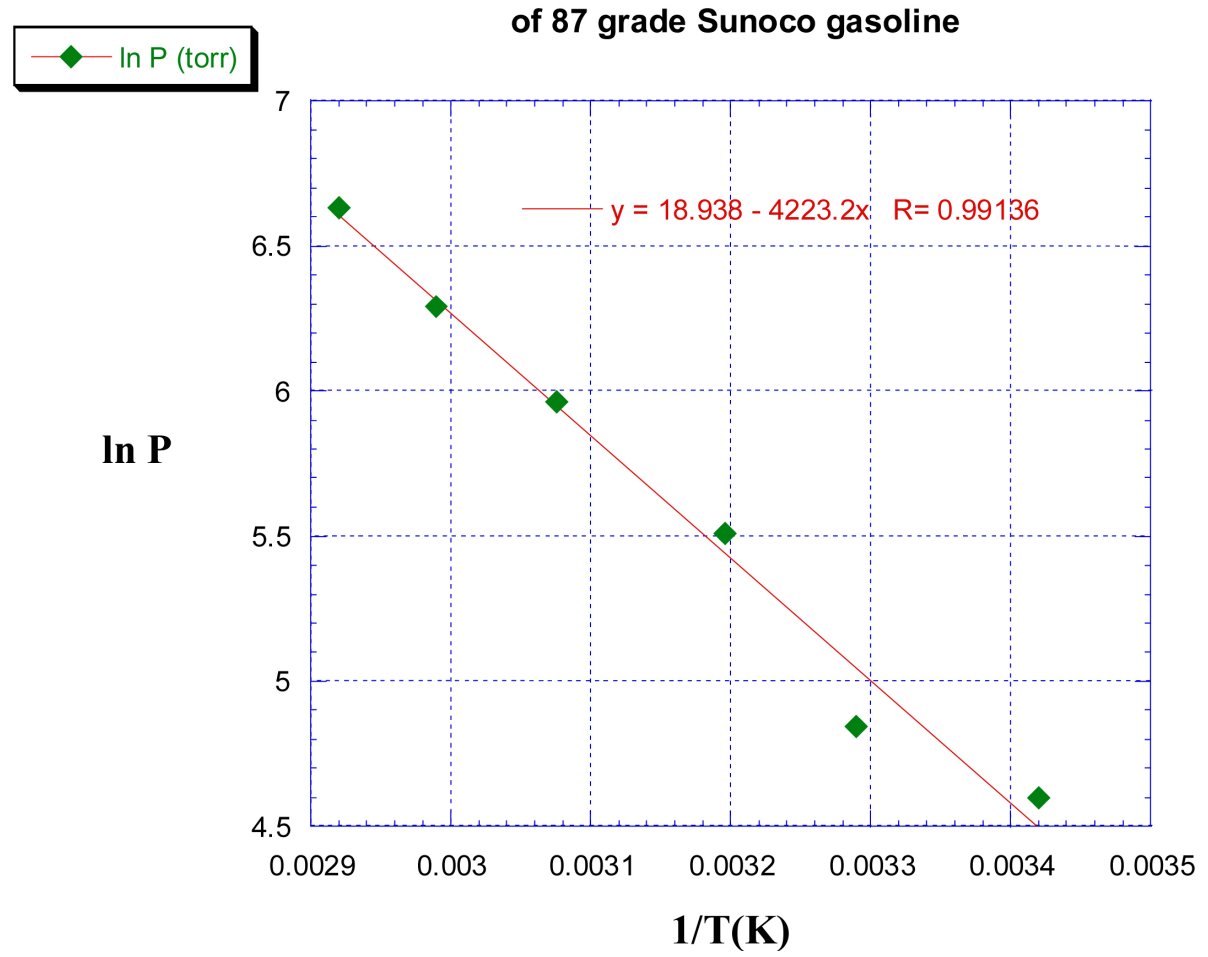

Figure 2. A plot of the $\ln P$ vs. $1 / T(K)$ of 87 octane rating Sunoco gasoline and the linear least squares regression fit of the empirical VP data. 
amassing VP data.

VP data was also amassed for n-heptane and n-octane in this study. Heptane was selected since it is used along with iso-octane to alter the octane rating of gasoline blends. In 1927, the octane rating was developed in order to control spontaneous combust of gasoline blends that produce a knocking sound in a standard engine. The straight $\mathrm{n}$-heptanes caused severe knocking in an engine and assigned a rating of 0 . In contrast, iso-octane (2,2,4-trimethylpentane) was assigned an octane rating of 100 since it did not cause knocking in engines [11]. During this investigation, VP measurements were acquired for n-octane (octane rating of -20) due to the lack of iso-octane.

The values for $\Delta H_{\text {vap }}$ and $\Delta S_{\text {vap }}$ for n-heptane and n-octane were predicted and computed in the same manner as the Sunoco 87 grade gasoline. An 87 octane gasoline can be described as having the knock resistance as a mixture of $13 \%$ n-heptane and $87 \%$ iso-octane by volume (v/v) respectively. In Figure 3, the linear least square regression fit of n-heptane yielded a slope of -4476.6 with a correlation coefficient (R) of 0.9994 . A value for $\Delta H_{\text {vap }}$ of $37.2 \mathrm{~kJ} / \mathrm{mol}$ was predicted, and a $\Delta S_{\text {vap }}$ of $100.1 \mathrm{~J} / \mathrm{mol} \cdot \mathrm{K}$ was computed using Trouton's Law. These values were within 3.5\% of the literature values [12]. For n-octane, a least square fit of the VP data as shown in Figure 4 resulted in a slope of -4698.8 and a correlation coefficient of 0.99935 . A value of $39.1 \mathrm{~kJ} / \mathrm{mol}$ for $\Delta H_{\text {vap }}$ was predicted, and a $\Delta S_{\text {vap }}$ value of $98.3 \mathrm{~J} / \mathrm{mol} \cdot \mathrm{K}$ resulted from this information. Both of these values were within $1.0 \%$ of their literature value [13].

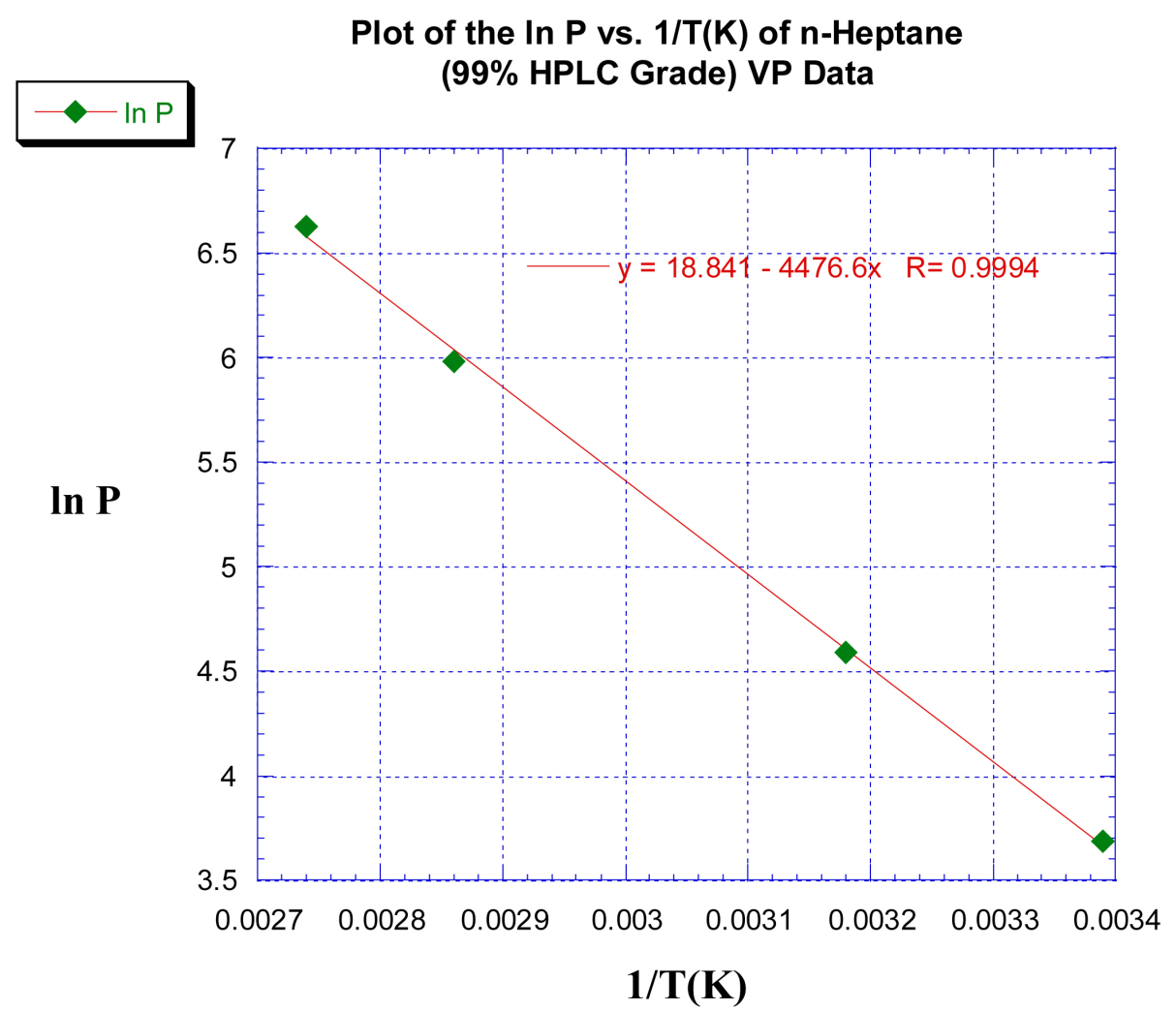

Figure 3. A plot of the $\ln P$ vs. $1 / T(K)$ of n-Heptane and the linear least squares regression fit of the empirical VP data. 
Plots of the In $P$ vs. 1/T(K) of n-Octane experimental and iso-Octane (2,2,4-trimethylpentane) literature data

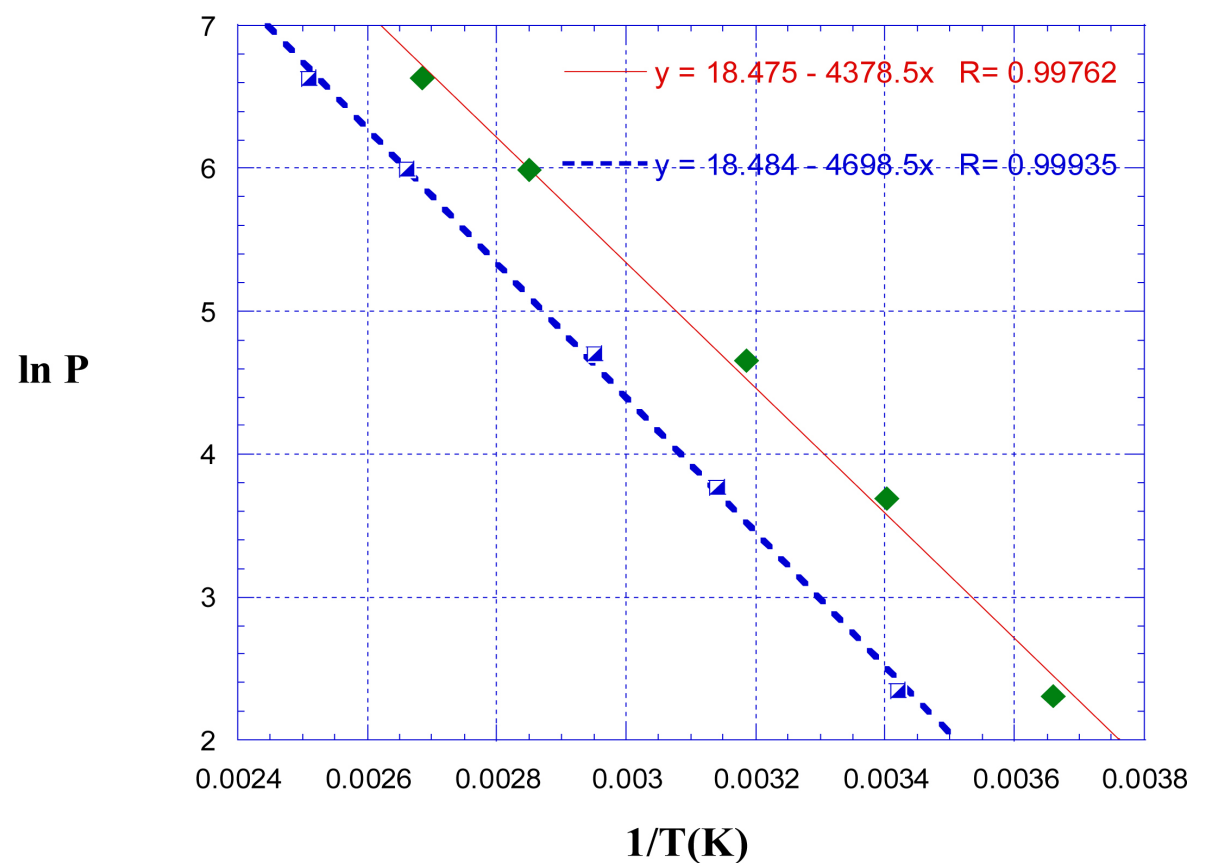

Figure 4. Plots of the $\ln P$ vs. $1 / T(K)$ of n-octane and iso-octane (2,2,4-trimethylpentane) and their linear least squares regression. The n-octane plot is of experimental VP data while the iso-octane is literature data. The n-octane is represented by half-filled (white/blue) squares and iso-octane by green diamonds.

A linear square regression fit was also applied to literature VP data of iso-octane [7]. This plot is shown in Figure 4 along with n-octane linear square regression fit of its empirical VP data. By examining the plots, it is readily apparent that the experimental and literature data do not overlap. However, the two lines are parallel yet their slopes are different; this indicates that two distinct values of $\Delta H_{\text {vap }}$ and $\Delta S_{\text {vap }}$ for n-octane and iso-octane (2,2,4-trimethylpentane) will be predicted and calculated. An enthalpy of vaporization $\left(\Delta H_{\text {vap }}\right)$ value of $36.4 \mathrm{~kJ} / \mathrm{mol}$ was predicted from the linear least squares fit of the iso-octane literature data. The $\Delta S_{\text {vap }}$ for iso-octane $97.8 \mathrm{~J} / \mathrm{mol} \cdot \mathrm{K}$ was computed from the literature. These values were within $3.5 \%$ when compared to the study by $\mathrm{Wu}$ et al. [14] [15].

Table 1 is a summation of the VP data amassed for water, EtOH, n-heptane, noctane, toluene, and Sunoco 87 grade gasoline. It contains the predicted value of $\Delta H_{\text {vap}}$, the computed values of $\Delta S_{\text {vap }}$, the slope of the line fit, and the correlation coefficient. It is important to notice that the correlation coefficient $\mathrm{R}$ for all of the linear least square regression fits are close to the value 1 . From Table 1, it is readily apparent that the experimental data parallels the literature data, which are shown in parentheses. The results of this investigation clearly demonstrate the exceptional capability and efficiency of our enhanced VP acquisition system for amassing VP data. We believe that this con- 
siderable body of original VP data would be invaluable to the petroleum industry since simulations of $\Delta H_{\text {vap }}$ are utilized extensively for evaluating and the optimization of processes in the manufacturing of gasoline blend [4] [16].

\section{Conclusion}

Vapor pressure data were obtained for 87 grade gasoline using the enhanced VP acquisition system described in this work. VP measurements were also acquired for n-heptane and n-octane, which served as reference and system calibration data. The VP data were also used to predict the enthalpy $\left(\Delta H_{\text {vap }}\right)$ and entropy of vaporization $\left(\Delta S_{\text {vap }}\right)$ of these VOCs from their line fits using the Clausius-Clayperon equation and Troutons Law respectively. The VP data and the predicted as well as calculated thermodynamic results were in excellent agreement with the literature results. This work has reinforced the validity and practicality of the enhanced VP acquisition system as an efficient tool.

\section{Acknowledgements}

The authors acknowledge Howard University, Dr. Clarence Lee (Executive Director) of the Howard University LS-AMP (Louis Stokes Alliance for Minority Participation) Program, Marquia Whitlock (LS-AMP Program), Monique Yvette McClung (LS-AMP Program), NSF (Grant Number HRD-1000286), and NIH-NIGMS (Grant Number T34GM105660).

\section{References}

[1] ASTM (1999) Annual Book of Standards. American Society for Testing and Materials, Philadelphia.

[2] da Silva, R., Cataluna, R., de Menezes, E.W., Samios, D. and Piatnicki, C.M.S. (2005) Effect of Additives on the Antiknock Properties and Reid Vapor Pressure of Gasoline. Fuel, 84, 951-959. http://dx.doi.org/10.1016/j.fuel.2005.01.008

[3] Riazi, M.R., Albahri, T.A. and AlQattan, A.H. (2003) Prediction of the Reid Vapor Pressure of Petroleum Fuels. Fuel Chemistry Division Preprints, 48, 478-479.

[4] Farsibaf, M.M., Golchinpour, M. and Barzegar, A. (2011) Global Optimization in Order to Find Blend Composition of Gasoline of Desired Octane Number Considering Ethanol as Octane-Booster. Proceeding of the 41 st International Conference on Computers \& Industrial Engineering.

[5] Chupka, G.M., Christensen, E., Fouts, L., Alleman, M.A., Matthew, A.R. and McCormick, R.L. (2015) Heat of Vaporization Measurements for Ethanol Blends up to 50 Volume Percent in Several Hydrocarbon Blendstocks and Implications for Knock in SI Engines. SAE International Journal of Fuels and Lubricants, 8, 251-263. http://dx.doi.org/10.4271/2015-01-0763

[6] Andersen, V.F., Andersen, J.E., Wallington, T.J., Mueller, S.A. and Nielsen, O.J. (2010) Vapor Pressure of Alcohol-Gasoline Blends. Energy Fuels, 24, 3647-3654.

http://dx.doi.org/10.1021/ef100254w

[7] Abernathy, S.M. and Brown, K.R. (2015) Using the Vapor Pressure of Pure Volatile Organic Compounds to Predict the Enthalpy of Vaporization and Computing the Entropy of Vaporization. Open Access Library Journal, 2, e1927. http://dx.doi.org/10.4236/oalib.1101927 
[8] Garland, C.W., Nibler, J.W. and Shoemaker, D.P. (2009) Experiments in Physical Chemistry. 8th Edition, McGraw-Hill, New York.

[9] Weast, R.C., Astle, M.J. and Beyer, W.H. (1984) CRC Handbook of Chemistry and Physics. In: Eds., R.C., CRC Press, Boca Raton, D199-D214.

[10] Balabin, R.M., Syunyaev, R.Z. and Kapov, S.A. (2007) Molar Enthalpy of Vaporization of Ethanol-Gasoline Mixtures and Their Colloid State. Fuel, 86, 323-327. http://dx.doi.org/10.1016/j.fuel.2006.08.008

[11] Girard, J.E. (2005) Principles of Environmental Chemistry. Jones and Bartlett Publishers, MA.

[12] Sipowska, J.T. and Wieczorek, S.A. (1984) Vapour Pressure and Excess Gibbs Free Energies of (Cyclohexanol + n-Heptane) between 303.147 and $373.278 \mathrm{~K}$. Journal of Chemical Thermodynamics, 16, 693-699. http://dx.doi.org/10.1016/0021-9614(84)90051-X

[13] Ewing, M.B. and Ochoa, J.C. (2003) The Vapour Pressure of n-Octane Determined Using Comparative Ebulliometry. Fluid Phase Equilibria, 210, 277-285. http://dx.doi.org/10.1016/S0378-3812(03)00174-2

[14] Wu, H.S., Pividal, K.A. and Sandler, S.I. (1991) Vapor-Liquid Equilibria of Hydrocarbons and Fuel Oxygenates. Journal of Chemical \& Engineering Data, 36, 418-421. http://dx.doi.org/10.1021/je00004a021

[15] http://webbook.nist.gov/chemistry/form-ser.html

[16] Gopinathan, N. and Sarai, D.N. (2001) Predict Heat of Vaporization of Crudes and Pure Components Revised II. Fluid Phase Equilibria, 179, 277-284. http://dx.doi.org/10.1016/S0378-3812(00)00501-X

\section{Submit or recommend next manuscript to OALib Journal and we will provide best} service for you:

- Publication frequency: Monthly

- 9 subject areas of science, technology and medicine

- Fair and rigorous peer-review system

- Fast publication process

- Article promotion in various social networking sites (LinkedIn, Facebook, Twitter, etc.)

- Maximum dissemination of your research work

Submit Your Paper Online: Click Here to Submit

Contact Us: service@oalib.com 